\title{
SEMIÓTICA DE LA PARODIA
}

\author{
SEMIOTICS OF PARODY \\ María José GARCÍA-RODRÍGUEZ \\ Universidad de Murcia \\ mariajose.garcia24@um.es
}

\begin{abstract}
Resumen: Este artículo indaga en la trascendencia de la semiótica y la filosofía del lenguaje para la manipulación de la dimensión connotativa esencial en el discurso de la imaginación. Para ello, la parodia servirá como punto de reflexión sobre el que la idea de semiotización podría definirse como un enclave textual de la memoria cultural. Siendo la parodia un fenómeno al que se adhieren (y que se adhiere a) valores historiográficos sin que a su definición pueda imponerse a una mirada histórica parcial (nacional, ideológica), hay en ella una asociación semiótica vertebrada por la historia de la filosofía del lenguaje, acompasada por la encarnación mítica y post-mítica de las relaciones materia-forma, individuo-colectividad. De esta manera, la aporía de todo acto de figuración se ejecuta en la parodia como una dialéctica que permite a los estudios literarios atender a la complejidad de la idea de Tradición en la especificidad de la forma estética.
\end{abstract}

Palabras clave: Parodia. Semiótica. Intertextualidad. Estética.

\begin{abstract}
This article explores the significance of semiotics and the philosophy of language for the manipulation of the connotative dimension in the discourse of the imagination. To this end, parody will serve as a point of reflection on which the idea of semiotization could be defined as a textual enclave of cultural memory. Since parody is a phenomenon to which historiographical values adhere (and which is adhered to) without its definition being subject to a partial (national, ideological) historical gaze, there can be observed in it a semiotic association vertebrate by the history of the philosophy of language, accompanied by the mythical and post-mythical incarnation of the relations matter-form, individual-collectivity. In this way, the aporia of every act of figuration is executed in parody as a dialectic that allows literary studies to attend to the complexity of the idea of Tradition in the specificity of aesthetic form.
\end{abstract}

Keywords: Parody. Semiotics. Intertextuality. Aesthetics.

\section{TEORÍA DE LA PARODIA COMO SÍNTOMA}

Este artículo se propone reconsiderar uno de los fenómenos artísticos que vivió un protagonismo intenso, aunque fugaz y perecedero, en los estudios literarios de finales del 
XX y los primeros años del XXI. La parodia fue foco de atención desde el estructuralismo y la hermenéutica - especialmente con la difusión (aunque no por ello indagación) de las investigaciones de Tynianov, Shklovsky y, sobre todo, Bajtín - para finalmente acabar por dispersarse en las formulaciones del nuevo historicismo y los estudios culturales sin que lo paródico haya llegado a consolidarse como una entidad operativa para la comprensión de lo estético. Observada ahora con mayor perspectiva, la teoría de la parodia se evidencia como reflejo del discurrir de los estudios literarios bajo los desafíos que se le imponen a la teoría actual. Las demandas de la cultura líquida, la lectura de lo estético en clave política, la mercantilización y retribalización sociocultural... En definitiva, una descomposición del marco de actuación de las Humanidades derivada de la pérdida de especifidad de lo estético, tanto por enjaular ${ }^{1}$ como por desatender las líneas definitorias del arte. En este punto, la Semiótica se revela una de las disciplinas de mayor alcance $^{2}$. Entendida en el seno de la escuela americana de la filosofía del lenguaje, la Semiótica responde a la reflexión estética transversal que demanda, no únicamente la acentuada circunstancia de la globalización, sino la propia naturaleza del arte como discurso de la imaginación.

Es por ello que el objetivo de este artículo es describir la performatividad y actuación de la Tradición en la dimensión ilocucionaria y perlocutiva del uso paródico del lenguaje, esto es, indagar en el funcionamiento semiótico de la parodia como modo de creación y recepción dentro del sistema estético. Para ello, tomaré como punto de arranque la disposición en estadios de José María Pozuelo Yvancos (2000) en la que se ha de advertir la distinción conceptual que supone sobre la concepción epistémica de la premodernidad, modernidad y postmodernidad en Rose (1993) y el ya clásico estudio de Lyotard (1999). Lejos de establecer una cronología de la parodia, la noción de estadio viene a sugerir una relación de status, no jerárquico, sino teórico, que pone el acento de la dualidad paródica en la vida, el arte o la lucha entre ambos. Si bien no es nuestro objetivo ahondar aquí en cada uno de los estadios (teniendo en cuenta que ya han sido establecidos como marco en la teoría de la parodia por los autores citados), tengamos en cuenta las pinceladas que matizan estéticamente cada uno de ellos:

I. El estadio premoderno de la parodia está regido por el sistema mítico del simbolismo tradicional. Más allá del extendido término de la carnavalización bajtiniana, los valores semióticos de la premodernidad anidan en la parodia a través del grotesco. Los estudios de Beltrán Almería (2002 y 2011) sobre esta estética fundacional son enormemente reveladores para comprender las relaciones de lo paródico con la dualidad de lo cruel y lo alegre, que ha nutrido el imaginario de lo cómico y marcado el desarrollo de las teorías del humor.

II. En la modernidad, el universalismo se desgaja. El individuo se construye como subjetividad frente a la institucionalización, a la oficialidad. La picaresca deviene la

\footnotetext{
${ }_{1}^{1}$ Aludo aquí a la idea desarrollada por Aparicio Maydeu (2015) en La imaginación en la jaula.

${ }^{2}$ A propósito de las relaciones semióticas entre la literatura y la dimensión multimedia, véase Romera Castillo, Gutiérrez Carbajo y García-Page, coords. (1997).
} 
estética fundacional de Occidente instaurando un punto de vista (Claudio Guillén, 1962; Lázaro Carreter, 1968; Francisco Rico, 1970) que conlleva un conflicto semiótico violento (Pittarello, 2015). Los lazos de materia y forma son en la modernidad reconfigurados sobre el ser frente al tener; un divorcio entre la verdad y el lenguaje del que se apropiará Cervantes con su Hidalgo, realizando un doble sistema semiótico de verosimilitud y credulidad, cuya interrelación cabalgará con Clavileño (Pozuelo Yvancos, 1993: 40; 2014: 77).

III. La posmodernidad, heredera del desencanto post-mítico de la modernidad, explora desde la semiología la reflexividad del lenguaje y el poder mitificador del signo literario dependiente de su valor histórico. Sobre la reificación marxista (verdinglichung) emergen las propuestas posmodernas con Baudrillard (1981) y Jameson (1989) que instauran la hiperrealidad. No hay nada salvo textualidad. El simulacro estético impone la performatividad como único modo de comunicación, instaurando un hermetismo pseudotribal para la interpretación del discurso.

Combinando tal recorrido de estadios de la parodia con la consciencia teórica de la textualidad, esa imagen-de-texto deja traslucir la complejidad misma del concepto de la tradición como práctica sincrónica y depositaria diacrónica, que aplicamos aquí a la parodia en tanto que elemento estético. ¿Qué implica tal consideración de los estadios y la textualidad para la definición de la parodia? Y, más aún, ¿cómo ayuda tal cruce conceptual para la comprensión de esta modalidad artística y del arte mismo como discurso estético? A continuación, me propongo explorar las problemáticas que plantean tales interrogantes, con la mirada puesta en la trascendencia de la semiótica y los actos de habla para la manipulación de la dimensión connotativa que asocia la literariedad con su propia construcción discursivo-enunciativa. Una vía teórica que viene a recuperar las propuestas de Tynianov (1924), Shklovsky (1925) y Bajtín (1975) junto a las semióticas de Barthes (1982), Lotman (1987) o Segre (1982), sobre la constitución de los signos cultural e ideológicamente motivados bajo los parámetros de los pactos pragmáticos de Austin (1955) desarrollados en la teoría de Ohmann (1971), Pratt (1975) y en España especialmente por Romera Castillo (coord. 1981 y 1998) y Domínguez Caparrós (1981).

\subsection{La construcción semiótica de la literariedad}

Afirmaba Linda Hutcheon en su reedición de $A$ Theory of Parody (1985): "I was lucky enough to begin this work at a time when semiotic theories of intertextuality were being developed (or reviewed) to explore the relationship of texts to texts, and the marks of the work of those theorists - from Bakhtin to Kristeva to Genette and beyond are evident in my thinking" (Hutcheon, 2000: xiii). Esta revisión de la intertextualidad desde el punto de vista semiótico como un desarrollo de las teorías formalistas hace de la teoría de Hutcheon una de las formulaciones adscritas a la importancia de las relaciones textuales más allá de las casillas categóricas de Genette (1980). Sin embargo, influida por los vientos de la postmodernidad, la perspectiva hermenéutica lleva a la autora a difuminar 
la especifidad de los valores semióticos de lo paródico principalmente por dos motivos: por la negación de la necesidad del elemento cómico y por una revisión ideológica de la tradición literaria. Hutcheon considera que la parodia está presente en todas las artes de nuestro tiempo. No es la única que proclama tal ubicuidad de la parodia; Gilles Lipovtesky en "La Societé humoristique" (1983) ya había descrito la postmodernidad como una ineluctable parody, en términos que él asocia a la comicidad grotesca bajtiniana. Si a ello le sumamos su inscripción metonímica de lo artístico (Chambers, 2010) y los fenómenos de la intertextualidad de la cultura de Internet (Boxman-Shabtai, 2018) se comprende cómo el alcance de la semiótica de la parodia se pierde en la propia naturaleza relacional del texto diciendo sin embargo poco sobre la teoría y el modo.

Ciertamente, la naturaleza modal del fenómeno paródico hace de este concepto una noción especialmente sensible a las variaciones epistemológicas de la filosofía del lenguaje que le han ido imponiendo distintas limitaciones teóricas. En este contexto entra en juego una concepción semiótica de la ontología (Bobes Naves, 2008) que debiera percibir el entramado que, desde la filosofía del lenguaje y la poética de la ficción, dibujan las fórmulas creativas, como lo es la parodia. Esto es, ante las problemáticas de dispersión y encasillamiento, la definición de parodia ha de partir de los valores semióticos hilvanados diacrónica y sincrónicamente, pero teniendo en todo momento como horizonte de definición lo estético. Nos aproximaríamos así desde la Semiótica a la Estética, en un salto que pretende responder a las leyes que rigen la imaginación a través de la gran evolución de los símbolos culturales. "La unidad de la imaginación no sólo tiene una dimensión sincrónica sino diacrónica. No sólo la imaginación es unitaria espacialmente sino temporalmente", afirma Beltrán Almería (2015: 372).

La transversalidad de la parodia, no como género o figura de discurso, sino como modo de enunciación y, más aún, no exclusivamente literario sino artístico, necesita de una visión teórica situada en el lenguaje como forma de expresión imaginaria. Los estadios arriba anunciados aspiran así sobreponerse a la compartimentación cronológica y espacial para describir los valores semiológicos de las interacciones hombre-lenguajemundo, germinales en la construcción de la tradición estética sobre la que discurre el arte. $\mathrm{Y}$ es que la asunción de una función poética del lenguaje sobre la que se arma toda enunciación literaria ha acabado inevitablemente afectando a la teoría de la parodia, pues la definición de lo paródico siempre se hará en diálogo con la idea de literariedad ${ }^{3}$. La parodia es un modo de creación estética cuya razón de ser última es la transitividad del valor artístico — como así la entiende Eagleton (1983), también Francisco Rico (1983), pero antes discutida en la Escuela de Tartu como valencia (Lotman, 1977) - y la credulidad que sostiene a las formas de expresión del lenguaje. Se trataría pues de distinguir las modelizaciones premodernas, modernas y postmodernas que definen el

\footnotetext{
${ }^{3}$ Para el desarrollo de una teoría de la parodia construida sobre las bases de esta interrelación de lo paródico con la literariedad tanto en su ejecución como acto de habla, como en el discurrir cultural de los estadios de la filosofía del lenguaje, véase García-Rodríguez (2020).
} 
armazón diacrónico de la parodia para determinar aquellas cualidades que intervienen sincrónicamente en toda actuación paródica (a lo que iré en el siguiente epígrafe).

La importancia histórica de la performatividad literaria es en este punto crucial para la delimitación de lo paródico. Aquella textualidad, enfrentada a lo vital, que servía a Pozuelo Yvancos (2000) para la construcción de los estadios desde las interacciones de la dualidad paródica se comprende mejor si acudimos a sus reflexiones sobre el lenguaje literario:

El hablar del narrador y el hablar de los personajes, los diálogos, etc., están semiotizados por una convención que es más extensa que la meramente literaria y en ella se basan las expectativas semánticas que el discurso confirma o rechaza y al hacerlo crea nuevos sentidos. La medida en que la problemática discursiva pone en juego todas las virtualidades de la semiótica, con especial incidencia en las relaciones pragmáticas (por ejemplo, competencia de lector) marca el grado de su enorme desarrollo en la teoría actual (Pozuelo Yvancos, [1989] 2010: 252).

Sobre esta idea de semiotización podría definirse la parodia como un enclave textual de la memoria cultural: un acto de habla marcado por la filosofía del discurso que manifiesta lo estético como literariedad. Cada palabra hace señas, que diría Foucault (1996). De esta reconsideración de la construcción de los discursos literarios como performatividad de la Tradición evidencia que tanto la escritura como la lectura orbitan en torno a la propia funcionalidad semiótica de los elementos enunciativos. La parodia evidencia en su realización hiperbólica las implicaturas que conforman la literariedad como contexto; gracias a la trascendencia diacrónica de los códigos se hará posible entonces su ejecución paródica sincrónica. Esto es, la diacronía de la Historia literaria (que prefiero entender como Tradición estética) se conjuga con la sincronía de la creación y la recepción del texto, pues es la literatura un uso del lenguaje que, pese a su ser diferido, existe en virtud de su actualización en el acto de écriture y lecture, un acto particular nacido de dicha trascendencia del sistema de enunciación: a sus estructuras se acercó Propp (1958) a través de la reiteración en el folclore; se intuye asimismo en el dialogismo bajtiniano; y fue consolidada en la perspectiva semiológica de Cesare Segre (1982) con su idea de interdiscursividad. 'Et c'est bien cela l'intertexte : l'impossibilité de vivre hors du texte infini”" (Barthes, 1973: 59).

El problema de la representatividad estético-literaria correlacionada con la literatura paródica y sus actos de lenguaje se observan igualmente en el funcionamiento del plano lingüístico. La unidad mínima metafórica ilumina los cambios epistemológicos del lenguaje simbólico sobre la línea diacrónica del contexto literario. No hay más que advertir su trascendencia en el quicio de los cambios de la premodernidad icónica a la modernidad conceptista, y, de esta última, a la posmodernidad de la simulación. El agotamiento que hace de las fórmulas metafóricas literarias simples fraseologismos (Lotman, 1981) repercute en la experimentación con un metalenguaje (figurativo) consciente de sí mismo. En primer lugar, bajo el impulso poético barroco de autodesignación y re-descripción ante la automatización estética; ejemplo de ello son los 
estudios de Robert Ball (1977; 1980), Pozuelo Yvancos (1979a) y Lía Schwartz (1984), donde se retoman las nociones de polifonía e intertextualidad desarrolladas por Kristéva (1969) para concebir la expansión de la poética barroca hispánica a partir de la metáfora como desautomatización discursiva. En segundo lugar, bajo un perspectivismo radical que reconoce el triunfo del artificio y subordina el signo al objeto: la teoría de la simulación de Baudrillard (1978) consagra el agotamiento del sistema metafórico fraguado en la modernidad, e instaura una consciencia inmanentista de todo código como fractura de lenguaje. Envueltos en las interpretaciones y representaciones del mundo y la individualidad, el eclecticismo actual remite a un polisistema semiológico en el que todo significa, todo es signo. La revolución tecnológica se ha volcado en fórmulas de reproducción, como así lo augurara Fredric Jameson (1991) y se estudian desde la semiótica (Romera Castillo, 1997); los medios de masas (tanto de producción, como de consumo) devienen una amplificación de la textualización cultural, entrando en la simulación otorga como valor empírico objetual, su valor asociativo: la capacidad de representar riqueza, singularidad o moda convierte al objeto en producto simbólico.

En suma, la parodia, instalada en la esfera semiótica de la literariedad y su manipulación estética, podrá observarse como un fenómeno al que se adhieren (y que se adhiere a) valores historiográficos sin que a su definición pueda imponerse a una mirada histórica parcial (nacional, ideológica). Hay en ella una asociación semiótica vertebrada por la historia de la filosofía del lenguaje, acompasada por la encarnación mítica y postmítica de las relaciones materia-forma, individuo-colectividad. La parodia es un modo de relación con la Tradición (construida filosófica y estéticamente) que permite la continuidad y el re-conocimiento de una diferenciación contextual propia. Esto es, la intertextualiad se sitúa como proceso de modelización estético (cultural) y hermenéutico (de-codificación) que evidencia la idea de Tradición como continuidad y ruptura (Aparicio Maydeu, 2013) más allá del análisis retórico o formalista de la intertextualidad. La idea de la Gramática de la creación de Steiner, que sirve de cómplice a Aparicio Maydeu en su aproximación a la tradición, nos eleva sobre el hipotexto e hipertexto genettiano para el estudio del uso semiótico de la parodia. Comprendiendo la literariedad como una cualidad estética transitiva que se ejecuta en cada acto de lenguaje sobre una Tradición del discurso imaginativo, la definición de la parodia se sitúa entonces en esa intersección entre los estadios y la textualidad. Podemos llegar así a la caracterización de la parodia como un modo estético que expone las condiciones comunicativas del discurso de la imaginación convocando en su realización la performatividad de la Tradición artística.

Ahora bien, ¿cómo lo hace?

\subsection{Actuación semiótica de la alteridad. La parodia, poética de extrañamiento}

La aproximación a las derivaciones de la literariedad como valor transitivo ejecutado en tres estadios aterriza (o debemos hacerla aterrizar) en la propia ejecución pragmática 
a través de las unidades semióticas del discurso. El nivel enunciativo-discursivo sobre el que se manifiesta la literariedad y su modalidad paródica. "No es exagerado decir que poseemos civilización porque hemos aprendido a traducir más allá del tiempo" (Steiner, 1998: 21). El análisis literario de los signos en funcionamiento se ha extendido desde algunas ramas de la estilística como un estudio de la ideología del lenguaje, que ha llevado a la historia de la literatura a una lectura en términos políticos. El nuevo historicismo y los estudios culturales que parecen dominar el panorama actual de la crítica y la formación universitaria son síntomas de la concepción romántica de las historias del arte como proyecciones nacionales del espíritu del tiempo (Zeitgeist) ${ }^{4}$. Tal noción del historicismo y de la estilística como ideología levanta fronteras interpretativas a las que actualmente se vienen respondiendo desde el arte (Didi-Huberman, 2000; Mieke Bal, 2016) y que, desde la literatura, han sido abordadas por conceptos como interdiscursividad (Segre, 1982) y, más recientemente, interdiscursividad germinativa (Pozuelo Yvancos, 2018) que en realidad tienden la mano a los distintos medios artísticos. Esto es, desde una consideración semiótica de la forma estética como una forma interior (Steiner aludía a una traducción interior) las relaciones inter-figurativas establecen un diálogo que fecunda en otros tiempos y en otros espacios. Con ello se pone de manifiesto que, si bien la estilística y el análisis cultural han experimentado un desarrollo que no necesita (o incluso va en contra) de la especificidad de lo estético, una de las vías que dan acceso a la forma estética (sin por ello enjaular su caracterización en la Retórica identitaria) será la revisión de cómo se traduce el discurso de la imaginación más allá del tiempo.

La literatura (y las artes) no labora directamente con emociones y valores sino con símbolos. Las emociones y los valores, para ser imágenes significantes, deben formar símbolos. El mundo de la oralidad (la prehistoria) elabora esas imágenes con un método distinto del mundo histórico. Y, dentro del mundo histórico, la Modernidad introduce una dimensión individualista que perturba la formación de símbolos tanto tradicional como premoderna (Beltrán, 2015: 376).

Es ilustrativo cómo la voz de Steiner acompaña a aproximaciones estético-filosóficas como la aquí citada de Luis Beltrán. De nuevo, estamos ante el compás de la literariedad que reúne las unidades de tiempo de la civilización en la diferenciación de su ejecución (pre)histórica; pero ahora la acercamos al terreno de lo textual a través de dos elementos: la traducción y el símbolo. La subjetividad individual que se summa a la colectividad del espíritu de la humanidad traduce más allá del tiempo a través de símbolos que se construyen desde la historia. El concepto de símbolo deviene así fundamental para la definición de lo paródico. Las figuras de sustitución han sido reconocidas por la semiótica como elementos de densidad y movilidad semántica en la codificación cultural del sentido. Recordemos las aportaciones de Lotman (1987) y Barthes (1982) sobre la metáfora y la metonimia en las que, precisamente, hacen referencia a su poder de

\footnotetext{
${ }^{4}$ Para una visión de las problemáticas de los estudios literarios derivadas del Zeitgeist, en su relación con lo ideológico y lo bello, véase Beltrán Almería (2020).
} 
connotación y su intraducibilidad ${ }^{5}$. Bajo la modalidad paródica, la condición de condensador y mediador del símbolo (Lotman, 1987) se hiperboliza y escenifica como un acto dialéctico semiótico. Más allá de los principios retóricos, y más allá de la composición ideológica (idea-forma), el modo paródico interviene en el universo semiológico de los símbolos. Lejos de ser una simple deformación de las relaciones de contenido y forma, la parodia emerge de la propia configuración y proyección amplificada del dialogismo del discurso literario como sistema de figuración simbólica.

La aporía del acto de figuración es en la parodia una dialéctica de la paradoja. Representándose en su continua negación semiótica, la parodia desdice los valores que finge acoger. Los símbolos en la parodia se ejecutan en una pugna entre Discurso e Historia, amplificando el recorrido de la subjetividad a la colectividad como una figuración cómica. Por el camino de la imaginación, la parodia proyecta los símbolos como imágenes cómicas $\mathrm{y}$, gracias a lo cómico, la aporía inherente a todo acto de figuración se representa. De ahí que la comicidad sea un elemento esencial de la parodia, el que sustenta su performatividad sobre la contradicción de su propio acto de lenguaje. La risa como elemento de la civilización está presente en el arte, desde la cultura primitiva de la oralidad, asociada a la liberación del lenguaje. La parodia se atiene a tal explosión de la imaginación para mediar en la construcción analógica de la figuración. Ya dejó constancia Foucault (1966) de la función cultural indispensable del loco como aquel sujeto enajenado en las analogías, el hombre de las semejanzas salvajes: "por todas partes ve únicamente semejanzas y signos de la semejanza; para él todos los signos se asemejan y todas las semejanzas valen como signos" (1968: 56). El trasunto de esta figura deviene evidente: "En el otro extremo del espacio cultural, pero muy cercano por su simetría, el poeta es el que, por debajo de las diferencias nombradas y cotidianamente previstas, reencuentra los parentescos huidizos de las cosas, sus similitudes dispersas" (1968: 56).

La parodia puede comprenderse así como la discursivización del loco-poeta que, sobre la reflexividad sintagmática y paradigmática, pone en marcha un doble mensaje (parodiado y parodiador) que hipertrofia el extrañamiento de su dualidad performativa. El uso paródico del lenguaje actualiza una doble codificación y una doble interpretación, consciente e inconsciente (eiron y alazon) del sistema semiótico en el que se inscriben. Por ello, el espíritu semiótico de lo paródico viene a ser una semántica de la alteridad. La construcción de símbolos como imágenes significantes a través de la estética grotesca, picaresca e hiperrealista se lleva a cabo en la parodia como una amplificación de la alteridad. El lector paródico no lo es de una metáfora o un símbolo cultural, sino de su revelación como juego pragmático en y del texto a través de una re-presentación situada y destinada a la otredad discursiva mediante la imagen hiperbólica. En este punto, vuelvo sobre la retórica de la imagen de Roland Barthes (1982) que considero una de las aportaciones semióticas más ilustrativas sobre esta condición de la parodia. El acervo

\footnotetext{
${ }^{5}$ La metáfora esconde todo un mundo teórico cuya complejidad no puede abordarse en este estudio. Ya la adelantaba Ortega en Las ideas sobre la novela (1925), como así lo estudió Lázaro Carreter (1990); Ricoeur indagó en ello en su fundamental libro La métafore vive (1975).
} 
cultural - los repertorios para Even-Zohar (1979), la reserva de sentido en Lotman (1987) - es expuesta en este texto de Barthes como una reserva de estereotipos (tomando como ejemplo la italianidad del anuncio de Panzani) que se actualizan gracias a una focalización que incluya la otredad como enclave semiótico. Es precisamente en este espacio donde la parodia adquiere su fuerza ilocucionaria e interviene en la alienación cultural en la que interactúa la subjetividad y la colectividad.

Los estudios pragmáticos que reparan en la parodia como acto de habla aluden a tal formulación amplificadora: "By association, the parody may also be meant to target movie stars in general and, by further association, all of Hollywood culture" (RossenKnill \& Richard, 1997: 743). Es el (des)encuentro de ambos niveles lo que abre paso a la parodia como un modo de comunicación estética basado en el neologismo, de la adjetivación de la sustantividad de la forma estética, que adquiere entonces su especificidad a partir de la imagen-de-discurso, imagen-de-género, imagen-deliterariedad. Al aproximarnos a las unidades textuales de la semiótica paródica se advierte cómo, a través de una figuración cultural consciente de su paradoja inherente como acto de representación de la Tradición estética, los símbolos se comportarán como formulaciones ajenas de voces que traducen más allá del tiempo las imágenes que significan un tiempo y espacio de concreción semántica. Cómicamente, la parodia enfatiza la connotación que todo código adquiere en su acto de habla. Para ello, discurso e historia se elaboran sobre sistemas semánticos que difieren en su construcción del símbolo. De ahí que podamos establecer otro punto de definición de la parodia. Se trata de un modo de ampliación del alcance literal del acto de lenguaje, al que difumina en sus límites y sitúa en la ambigüedad de lo que es y lo que no es: la parodia juega a ser imitación siendo en realidad deformación amplificada autorreferencial, pues su objetivo no es referirse a sino representarse como.

\section{CONCLUSIONES}

"The great promise of semiotics is the possibility it represents of welding together both language and text analysis and the analysis of pragmatic and ideological context" (Segre, 1978: 52). Queda claro que la naturaleza transmedial de la parodia hace necesaria una concreción que exceda lo estructural y formal al abrigo del espacio semiótico de definición estética. Sin un enfoque teórico que se aproxime al signo y a los acentos ideológico-culturales que lo sitúan en la actualización histórica y la manipulación simbólica, la parodia pierde su significación. El modo paródico puede entonces definirse como la imaginación disociativa de las relaciones semántico-formales establecidas por la estética en su performatividad. Es en el nudo semiótico-pragmático de la figuración donde actúa la parodia, eludiendo el valor objetual para jugar con su imagen. La desideologización y despolitización de los estudios literarios solo será posible con un reconocimiento de la autonomía y la relatividad de la obra de arte, construida sobre leyes estéticas que brotan de los principios ontológicos (Beltrán, 2015). 
"El azul de Veronese habita en el azul de Klein: de forma permanente, la tradición está presente en estado de latencia" (Aparicio Maydeu, 2013: 15). La idea de la Tradición deviene fundamental en la aproximación a la intertextualidad como elemento de análisis artístico. Entender cómo el acervo cultural que condensa todo símbolo como mediador en la codificación y decodificación a través del tiempo y el espacio: ¿no sería también el azul de Klein una habitación para el de Veronese? Las interrelaciones sobre las que se aprehende y expresa lo estético son fundamentales para el estudio de la literatura, cuanto más, para sus modos de representación, en este caso, paródicos. Si la tradición habita en la forma estética, la parodia hace de tal ocupación un asentamiento turístico, hipertrofiando y transportando los signos semióticos de definición para convertirlos en una imagen. El resultado: China Town, Las Vegas, Little Italy... Juegos cómicos que no solo laten, sino explotan ruidosamente ante el lector.

I recall a friend once saying that the god of parody, if there were one, would be Janus, with his two heads facing in two directions at once. Increasingly though, I find myself invoking Hermes, the mediations, for Hermes is the god of both thieves and merchants, cheating and commerce. What better deity to preside over the thinking about parody's transgressing and authorizing impulses, its challenges to as well as reinscriptions of authority? (Hucheon, 2000: xvii).

La dualidad de la parodia ha sido desde su origen epistemológico la fuente de su definición ( $\pi \alpha \rho \alpha$, 'frente a', 'junto a'). Las teorías de la parodia tienden a agruparse sobre una de las acepciones, considerándola bien como una imitación bien como una subversión (formal, ilocucional y/o hermenéutica). Lo cierto es que la parodia se comprende mejor si se piensa en ella como una réplica, como contestación a y repetición de. La manifestación misma de la imaginación como figuración de lo que es y no es, de lo que se hace imagen, pero está ausente.

La parodia es Hermes, porque su dualidad responde a su condición de mediador, el mensajero entre la divinidad y los hombres, entre la materia y la forma, la tradición y el acto de lenguaje. El creador es el nuevo Prometeo (Aparicio Maydeu, 2013), encadenado a la Tradición como condición ingénita de todo acto creativo y cuyos artefactos trajeron a Pandora $\mathrm{y}$, con ella, la terrible condena del divorcio de la esencia y la apariencia (Beltrán, 2006). La mirada semiótica desde la filosofía del lenguaje evidencia esta composición del mito de la parodia que viene a explicar cómo el discurso de la imaginación se construye sobre los mecanismos de la figuración estética a través de la mediación de Hermes, la astucia de Prometeo y la escisión de Pandora.

\section{REFERENCIAS BIBLIOGRÁFICAS}

ApARICIO MAYDEU, J. (2013). Continuidad y ruptura. Una gramática de la tradición en la cultura contemporánea. Madrid: Alianza Editorial. 
(2015). La imaginación en la jaula: razones y estrategias de la creación coartada. Madrid: Cátedra.

Austin, J. L. (1975). How to do things with words: The William James Lectures delivered at Harvard University in 1955. London: Oxford University Press.

BAJTín, M. (1971 [1965]). La cultura popular en la Edad Media y en el Renacimiento. El contexto de François Rabelais, J. Forcat, \& C. Conroy (trads.). Barcelona: Barral Editores.

(2019 [1975]). La novela como género literario, L. Beltrán Almería (ed.). Zaragoza: Prensas de la Universidad de Zaragoza.

BAL, M. (2016). Tiempos trastornados. Análisis, historias y políticas de la mirada, Remedios Perni Llorente (trad.). Madrid: Akal.

BALL, R. (1977). Góngora's Parodies of Literary Convention. Michigan: UMI.

(1980). "Imitación y parodia en la poesía de Góngora”. En Actas del Sexto Congreso de la Asociación Internacional de Hispanistas celebrado en Toronto del 22 al 26 de agosto de 1977, 90-93. Toronto: Department of Spanish \& Portuguese, University of Toronto. Se cita a partir de la edición digitalizada por la Biblioteca Virtual Miguel de Cervantes, sin página. Disponible en línea: http://data.cervantesvirtual.com/manifestation/743574 [22/02/2021].

BARTHES, R. (1961) “Le message photographique”. Communications 1, 127-138.

(1976). Le plaisir du texte. París: Éditions du Seuil.

(1986 [1982]). “Retórica de la imagen”. En Lo obvio y lo obtuso, 27-43. Barcelona: Paidós.

BAUDRILlARD, J. (1978). Cultura y simulacro. Barcelona: Kairós.

BELTRÁN AlmERÍA, L. (2002). La imaginación literaria: la seriedad y la risa en la literatura occidental. Barcelona: Montesinos.

(2006). "Pandora en la encrucijada de los tiempos". Culturas Populares 2, 1-9.

(2011). Anatomía de la risa. Sonora: Ediciones sin Nombre.

(2015). “Ontología, teoría de la imaginación e historia literaria". Rilce 31.2, 365380.

(2020). "Sin fronteras. Antinomias de los estudios literarios". Iztapalapa. Revista de ciencias sociales y humanidades 41.89, 9-27.

Bobes Naves, C. (2008). Crítica del conocimiento literario. Madrid: Arco / Libros.

BOXMAN-SHABTAI, L. (2018). "Reframing the popular: A new approach to parody". Poetics 67, 1-12.

Chambers, R. (2010). Parody: The Art that Plays with Art. New York: Peter Lang.

Didi-Huberman, G. (2000). Ante el tiempo: historia del arte y anacronismo de las imágenes. Buenos Aires: Adriana Hidalgo.

Domínguez CAPARRós, J. (1981). "Literatura y actos de lenguaje”. Anuario de Letras: Lingüística y Filología 19, 89-132.

Eagleton, T. (1996). Literary Theory. An Introduction. Oxford: Blackwell Publishing. Even-Zohar, I. (1979). "Polysystem theory”. Poetics Today 1.1/2, 287-310. 
FOUCAULT, M. (2010 [1968]). Las palabras y las cosas: una arqueología de las ciencias humanas, E. C. Frost (trad.). Madrid: Siglo XXI.

(1996). De lenguaje y literatura. Barcelona: Paidós.

GARCíA-RodríGUEZ, M. J. (2020). Teoría de la parodia. Madrid: Visor Libros.

GenetTe, G. (1989 [1982]). Palimpsestos: la literatura en segundo grado, C. Fernández Prieto (trad.). Madrid: Taurus.

Guillén, C. (2015 [1962]). Literature as System: Essays toward the Theory of Literary History. New Jersey: Princeton University Press.

Hutcheon, L. (2000). A Theory of Parody. The Teachings of Twentieth-Century Art Forms. Illinois: University of Illinois Press.

JAMESOn, F. (1989). Postmodernism, or the Cultural Logic of Late Capitalism. Duke University Press.

LÁzAro CARreter, F. (1970). "Para una revisión del concepto "novela picaresca"”. En Actas del Tercer Congreso Internacional de Hispanistas, Carlos H. Magis (coord.), 27-45. México: El Colegio de México.

(1990). “Ortega y la metáfora”. En De poética y poéticas, 112-128. Madrid: Cátedra.

Lipovetsky, G. (1981). "La société humoristique”. Le Débat 3.10, 49-67.

LotMAn, J. (1990 [1987]). "The Symbol in the System of Culture". Universe of the Mind: A Semiotic Theory of Culture, 102-111. Indiana: Indiana University Press.

(2004 [1992]). Culture and Explosion, M. Grishakova (ed.) \& W. Klark (trad.). Berlin: Mouton de Gruyter.

LyOtARD, J.-F. (1999). The Postmodern Condition: a Report on Knowledge. Manchester: Manchester University Press.

PitTarello, E. (2015). "Si las cosas ya no están a mano: imágenes del Lazarillo y el Quijote". Arizona Journal of Hispanic Cultural Studies 19, 183-201.

Ohmann, R. (1971). "Speech Acts and the Definition of Literature". Philosophy \& Rhetoric 4.1, 1-19.

ORTEGA Y GASSET, J. (2016 [1925]). La deshumanización del arte e ideas sobre la novela. Madrid: Austral.

Pozuelo Yvancos, J. M. (1979). El lenguaje poético de la lírica amorosa de Quevedo. Murcia: Universidad de Murcia. (2010 [1988]). Teoría del lenguaje literario. Madrid: Cátedra. (1993). Poética de la ficción. Madrid: Síntesis.

(2000). "Parodiar, rev(b)elar". Exemplaria 4, 1-18.

(2014). "El Quijote y la parodia moderna". En La invención literaria: Garcilaso, Góngora, Cervantes, Quevedo y Gracián, 65-78. Salamanca: Universidad de Salamanca.

(2018). "Diálogo germinativo de los textos: Javier Marías ante un motivo de Juan Benet". Revista de Occidente 450, 99-114.

PratT, M. L. (1975). Toward a Speech Act Theory of Literary Discourse. Bloomington: Indiana University Press. 
Propp, V. (1968 [1958]). Morphology of the Folktale. Texas: University of Texas Press. RICO, F. (1983 [1970]). La novela picaresca y el punto de vista. Barcelona: Seix Barral. "Literatura e historia de la literatura". Boletín Informativo de la Fundación Juan March 127, 3-16.

Ricoeur, P. (1975). La Métafore vive. París: Éditions du Seuil.

Romera Castillo, J. (1997). "Literatura y nuevas tecnologías". En Literatura y multimedia: actas del VI Seminario Internacional del Centro del Instituto de Semiótica Literaria, Teatral y Nuevas Tecnologías de la UNED, J. Romera Castillo, F. Gutiérrez Carbajo y M. García-Page (coords.), 13-82. Madrid: Visor Libros.

(1998) Literatura, teatro y semiótica: método, prácticas y bibliografía. Madrid: UNED.

Romera Castillo, J., COORD. (1981). La literatura como signo. Madrid: Playor.

Romera Castillo, J.; Gutiérrez Carbajo, F., y García-Page, M., CoOrds. (1997). Literatura y multimedia: actas del VI Seminario Internacional del Centro del Instituto de Semiótica Literaria, Teatral y Nuevas Tecnologías de la UNED. Madrid: Visor Libros.

Rose, M. (1979). Parody: Meta-Fiction. London: Croom Helm. (1993). Parody: Ancient, Modern and Post-Modern. Cambridge: Cambridge University Press.

RoSSEN-KNILL, D. F. \& RichaRD, H. (1997). “The pragmatics of verbal parody”. Journal of Pragmatics 27.6, 719-752.

SEgRe, C. (1978). "Culture and modeling systems”. Critical Inquiry, 4.3, 525-537.

(1982). "Intertestuale-Interdiscursivo. Appunti per una fenomenología delle fonti". En La parola ritrovata. Fonti e analisi, C. Di Girolamo, \& I. Paccagnella (coords.), 15-28. Palermo: Sellerio.

SHKLovsKy, V. (1990 [1921]). “The novel as parody: Sterne's Tristram Shandy”. Theory of Prose, 147-170. Chicago: Dalkey Archive Press.

SteINER, G. (1980). Después de babel. Aspectos del lenguaje y de la traducción. Madrid: Fondo de Cultura Económica.

TyniAnOV, J. (1979 [1921]). "Dostoevsky and Gogol: Towards a Theory of Parody". En Dostoevsky and Gogol: Texts and Criticism, P. Meyer \& S. Rudy (eds.), 101-118. Ann Arbor: Ardis.

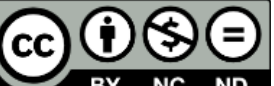

This work is licensed under a Creative Commons AttributionNonCommercial-NoDerivatives 4.0 International (CC BY-NC-ND).

Fecha de recepción: 08/02/2021

Fecha de aceptación: 08/03/2021

(C) UNED. Revista Signa 31 (2022), pp. 401-413

DOI: https://10.5944/signa.vol31.2022.29860

ISSN digital: 2254-9307. ISSN papel: 1133-3634 